\title{
Tryptophan-dependent sensitized photoinactivation of colicin E1 channels in bilayer lipid membranes
}

\author{
T.I. Rokitskaya ${ }^{a}$, S.D. Zakharovev, ${ }^{b, c}$ Yu.N. Antonenko, ${ }^{a}, *$ E.A. Kotova ${ }^{a}$, W.A. Cramer ${ }^{b}$ \\ ${ }^{a}$ A.N. Belozersky Institute of Physico-Chemical Biology, Moscow State University, Moscow 119899, Russia \\ ${ }^{\mathrm{b}}$ Department of Biological Sciences, Purdue University, West Lafayette, IN 47907, USA \\ ${ }^{\mathrm{c}}$ Institute of Basic Problems of Biology, Russian Academy of Sciences, Puschino, Moscow Region 142290, Russia
}

Received 26 June 2001; revised 31 July 2001; accepted 31 July 2001

First published online 22 August 2001

Edited by Maurice Montal

\begin{abstract}
The bacterial toxin colicin E1 is known to induce voltage-gated currents across a planar bilayer lipid membrane. In the present study, it is shown that the colicin-induced current decreased substantially upon illumination of the membrane in the presence of the photosensitizer, aluminum phthalocyanine. This effect was almost completely abolished by the singlet oxygen quencher, sodium azide. Using single tryptophan mutants of colicin E1, Trp495 was identified as the amino acid residue responsible for the sensitized photodamage of the colicin channel activity. Thus, the distinct participation of a specific amino acid residue in the sensitized photoinactivation of a defined protein function was demonstrated. It is suggested that Trp495 is critical for the translocation and/or anchoring of the colicin channel domain in the membrane. (C) 2001 Published by Elsevier Science B.V. on behalf of the Federation of European Biochemical Societies.
\end{abstract}

Key words: Lipid bilayer; Ion channel; Toxin; Tryptophan; Reactive oxygen species; Photosensitized inactivation

\section{Introduction}

The process of sensitized photoinactivation is basic for photodynamic therapy which is becoming common for the treatment of several types of cancer [1,2]. Photodynamic action on cells presents a vivid example of the effect of oxidant stress on biological systems because it is based on the interaction of photosensitizer-generated reactive oxygen species with cellular components. In particular, biological membranes have been shown to represent one of the primary targets of the photodynamic action on cells $[3,4]$. Studies of photodynamic effects on membranes have revealed specific modifications of ionic currents in nerve, skeletal muscle, cardiac and some other cells [5-9], as well as of ion fluxes associated with the mitochondrial permeability transition pore [10].

The data obtained at the level of single ionic channels indicate that photomodification of calcium $[11,12]$ and potassium $[13,14]$ channels in bilayer lipid membranes (BLMs) is caused by the attack of photosensitizer-generated reactive oxygen species on channel-forming proteins leading to damage of sensitive amino acid residues. An alternative explana-

\footnotetext{
*Corresponding author. Fax: (7)-095-939 3181.

E-mail address: antonen@genebee.msu.su (Y. Antonenko).
}

Abbreviations: BLM, bilayer lipid membrane; P178, 178-residue C-terminal colicin E1 channel polypeptide tion of the photodynamic alteration of ionic channel activity might be based on the photomodification of the lipid environment of the channel proteins [14]. The results of investigation of the photosensitized inactivation of ionic channels formed by gramicidin A (15-residue peptide) in BLM provide evidence in favor of channel photomodification via the first mechanism. Visible light irradiation of gramicidin channels in the presence of a photosensitizer suppressed gramicidininduced conductance of BLM, due to reduction of the number of open channels. This was associated with damage to tryptophan residues [15-19]. Tryptophan residues have been identified that are crucial for maintaining the structure and function of gramicidin channels [20-22], certain channel-forming toxins [23], and membrane receptor proteins [24].

Although gramicidin is useful as a first step towards understanding the mechanisms of the photodynamic effect on natural channels, it is reasonable to study a more complex channel-forming protein, e.g. colicin E1. This 522-residue protein belongs to a group of bacteriocins which exert their lethal action by forming a voltage-gated channel [25] in the Escherichia coli cytoplasmic membrane as a result of insertion of the C-terminal 170-190-residue channel domain into the membrane [26-28]. The channel domain contains three Trp, two His and nine Tyr residues [27]. Since Trp, His and Tyr residues are known to serve as targets of sensitized photomodification of proteins [2,29-32], it is reasonable to propose that colicin E1-induced bilayer conductance can be altered upon irradiation of the BLM in the presence of a photosensitizer. Here, we present the data on photoinactivation of colicin E1 channels in BLM sensitized by aluminum phthalocyanine. The findings of this work reveal the specific amino acid residue in the channel protein which is responsible for the channel photoinactivation.

\section{Materials and methods}

Single Trp or Trp-less mutants of colicin E1 were prepared by replacing pertinent Trp residues (Trp424, Trp460, and/or Trp495) with Phe [33,34]. The single Trp mutant Y356W [35] was also used in this study. The 178-residue C-terminal colicin E1 channel polypeptide, P178, was prepared by thermolysin proteolysis of intact colicin E1 [36].

Since it is known that incorporation of colicin channels into BLM requires acidic $\mathrm{pH}$ and the presence of anionic lipids [26,37,38], BLMs were formed from a $2 \%$ solution of $1: 3(\mathrm{w} / \mathrm{w})$ mixture of diphytanoylphosphatidylserine (DPhPS) and diphytanoylphosphatidylcholine (DPhPC, both Avanti Polar Lipids, Alabaster, AL, USA) in $n$-decane (Merck, Darmstadt, Germany) by the brush technique [39] on a $0.55 \mathrm{~mm}$ diameter hole in a Teflon partition separating two aqueous 
compartments. The bathing aqueous solution was $0.12 \mathrm{M} \mathrm{KCl}, 10 \mathrm{mM}$ $\beta$-alanine, $\mathrm{pH}$ 4.0. Colicin (P178) and its mutants were added to the cis-side of a membrane. The channel former incorporated spontaneously into the membrane. The conductance usually reached steady state within $30 \mathrm{~min}$ after the addition of colicin.

The electric current, $I$, was recorded under voltage-clamp conditions. The current was measured by means of an OES-2 patch-clamp amplifier (Opus, Moscow, Russia), digitized by LabPC 1200 (National Instruments, Austin, TX, USA) and analyzed with the help of WinWCP Strathclyde Electrophysiology Software designed by J. Dempster (University of Strathclyde, UK). In most experiments, the data sampling interval was set to $0.5 \mathrm{~s}$. The voltage was applied to BLM with $\mathrm{Ag}-\mathrm{AgCl}$ electrodes placed directly into the cell. The photosensitizer, aluminum phthalocyanine with three sulfonate groups $\left(\mathrm{AlPcS}_{3}\right.$, Porphyrine Products, Logan, UT, USA), was added to the bathing solution at the trans-side of the BLM. A tungsten lamp providing an incident power density of $30 \mathrm{~mW} / \mathrm{cm}^{2}$ was used for illumination. The lamp was placed at the cis-side of the membrane. The experiments were carried out at room temperature $\left(20-22^{\circ} \mathrm{C}\right)$.

\section{Results}

The ionic current through BLM induced by the colicin E1 channel domain (P178) displayed the characteristic voltage dependence [40]: it increased rapidly when a cis-side positive voltage was applied to BLM, and decreased almost to zero level when a negative voltage was applied (Fig. 1).

Irradiation of BLM with continuous visible light in the presence of the photosensitizer $\mathrm{AlPcS}_{3}$ resulted in a decrease in the colicin-induced current that did not recover after switching the light off (Fig. 1). In line with $\mathrm{AlPcS}_{3}$ being a potent generator of singlet oxygen [41], the colicin photoinactivation was suppressed by sodium azide (Fig. 2), the wellknown singlet oxygen quencher [31], thus favoring the photodynamic mechanism of the process under study.

To identify residues involved in the process of colicin E1 photoinactivation, experiments with site-directed mutants
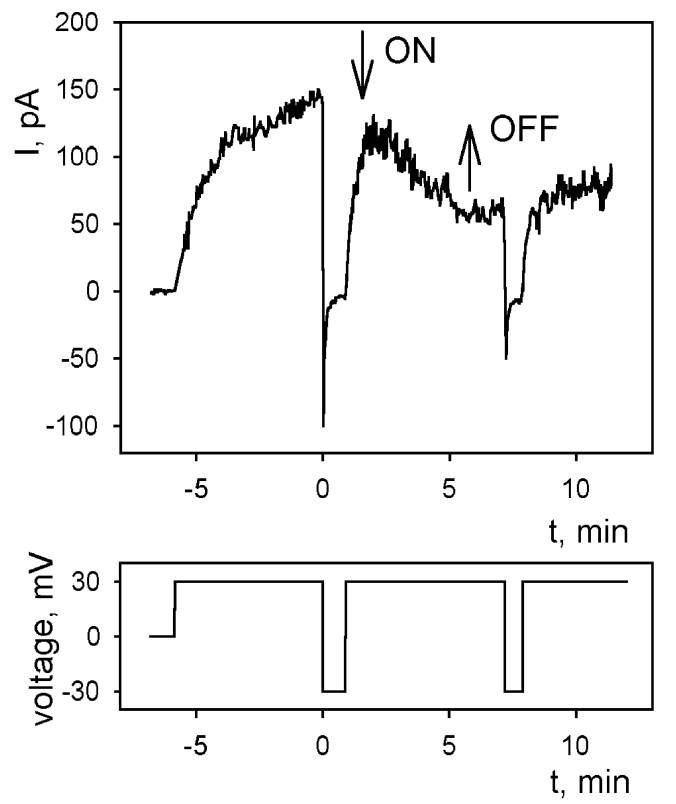

Fig. 1. Sensitized photoinactivation of colicin-induced currents $2 \mu \mathrm{g} / \mathrm{ml}$ of colicin E1 (P178) was added at the cis-side of a planar BLM made of DPhPC (75\%) and DPhPS $(25 \%)$. The solution was $0.12 \mathrm{M} \mathrm{KCl}, 10 \mathrm{mM} \beta$-alanine, $\mathrm{pH}$ 4.0. $1 \mu \mathrm{M} \mathrm{AlPcS}$ was added at the trans-side. Light $\mathrm{ON}$ and $\mathrm{OFF}$, switching the visible light on and off, respectively.

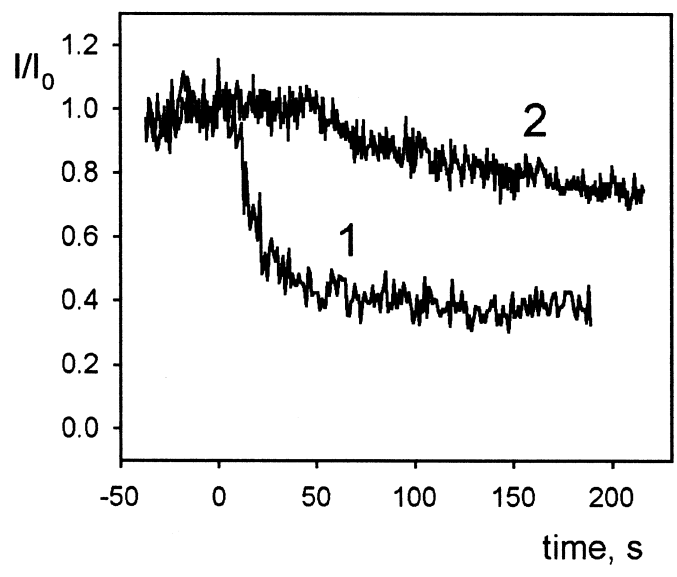

Fig. 2. Effect of the quencher of reactive oxygen species, sodium azide, on the sensitized photoinactivation of colicin-induced currents. $2 \mu \mathrm{g} / \mathrm{ml}$ of colicin $\mathrm{E} 1$ (P178) was added at the cis-side of a planar BLM made of DPhPC $(70 \%)$ and DPhPS $(30 \%)$. The solution was $0.12 \mathrm{M} \mathrm{KCl}, 10 \mathrm{mM} \beta$-alanine, $\mathrm{pH} 4.0 .1 \mu \mathrm{M} \mathrm{AlPcS}_{3}$ was added at the trans-side. Light was applied at $t=0 \mathrm{~s}$. In curve 2, $30 \mathrm{mM} \mathrm{NaN}$ was added at both sides of the BLM before switching the light on. $I_{0}$ was approximately $150 \mathrm{pA}$.

were performed. The channel activity of Trp-less P178, containing two His and nine Tyr residues, was not photoinactivated (Fig. 3B), thereby showing the major role of damage to tryptophans in P178 photoinactivation.

The contribution of each Trp residue to this process was studied using single tryptophan mutants. The mutants with Trp at positions 356 (helix I), 424 (helix V) or 460 (VI-VII interhelix loop), Y356W, W424 and W460, respectively, were insensitive to irradiation in the presence of $\mathrm{AlPcS}_{3}$ (Fig. 3CE), while the mutant with Trp at position 495 (helix IX), W495, exhibited high sensitivity to the photodynamic action under these conditions (Fig. 3F). Thus, it can be concluded that the presence of Trp495 is required for photoinactivation of the colicin E1 channel to occur, whereas Trp residues at positions 356, 424 or 460 are not involved in the photoinactivation of the P178 channel activity.

\section{Discussion}

The results of our experiments have shown that ion channels formed by colicin E1 in BLM undergo photoinactivation, when exposed to irradiation with visible light in the presence of the photosensitizer. Sensitivity of colicin photoinactivation to azide provided evidence in favor of participation of singlet oxygen in this process.

As judged from the experiments with the W495 mutant (Fig. 3F), colicin photoinactivation depends on the presence of Trp495, which is located in $\alpha$-helix IX of the colicin channel-forming domain [28]. Trp495 is in or near the apex of the hydrophobic hairpin (helices VIII-IX) that is believed to anchor the channel domain in the membrane [27]. It would thus be localized in the interfacial layer on the trans-side of the membrane relative to the side of colicin addition. It is known that location in the membrane interfacial region is characteristic of Trp residues of proteins that are integrated into the membrane $[42,43]$. Since all the other single tryptophan mutants, namely those retaining Trp424 in helix V or Trp460 in the VI-VII interhelix loop, as well as the Y356W mutant with Trp356 introduced by mutagenesis into helix I, are not sus- 

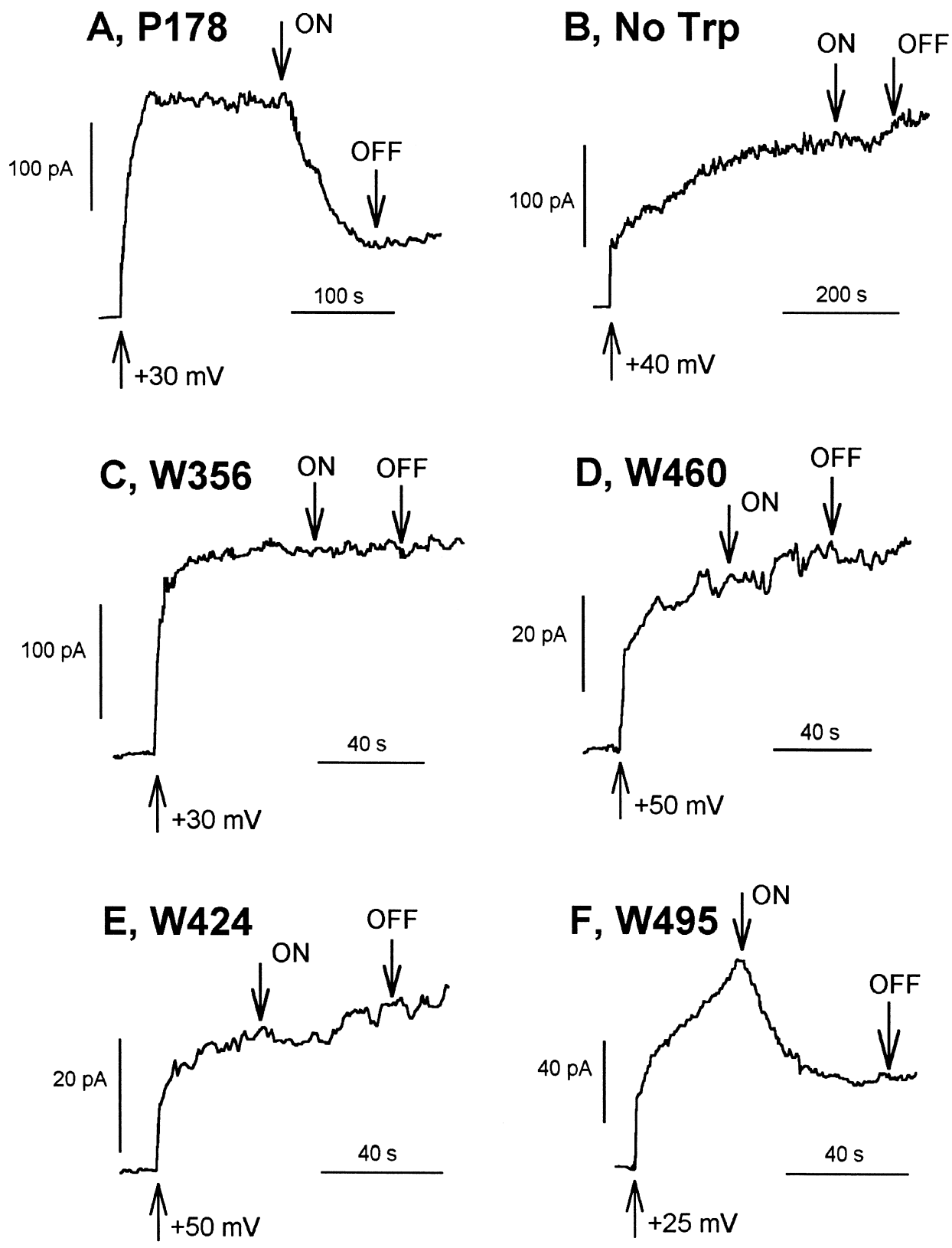

Fig. 3. Sensitized photoinactivation of colicin mutants. Colicin E1 (P178) mutants were added at the cis-side of a planar BLM made of DPhPC $(75 \%)$ and DPhPS (25\%). The solution was $0.12 \mathrm{M} \mathrm{KCl}, 10 \mathrm{mM} \beta$-alanine, $1 \mu \mathrm{M} \mathrm{AlPcS}$ (trans), pH 4.0. ON and OFF, switching the visible light on and off, respectively.

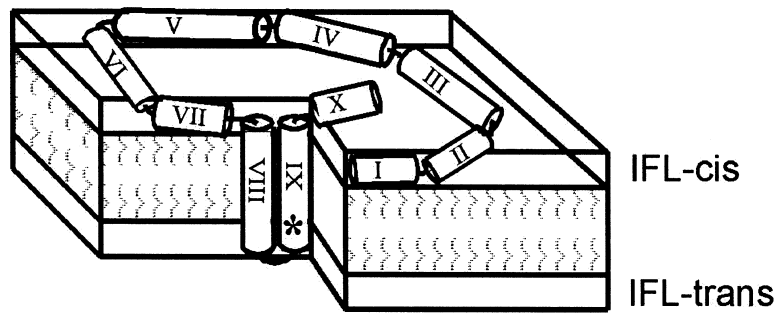

Fig. 4. Diagram illustrating that anchoring of helices VIII-IX hairpin in transmembrane orientation is facilitated by location of Trp495 in the trans-side interfacial layer (IFL-trans). The position of Trp495 is shown by a star. Helices are marked by Latin numbers. ceptible to the photodamage, it is inferred that Trp495 has a unique role in photoinactivation and is most likely involved in the process of channel formation. It is proposed that this residue is important in the translocation and/or anchoring of the VIII-IX helical hairpin in the membrane during colicin insertion, as described in [35] and depicted in Fig. 4. The ability of the Phe495 mutant to function like the wild type Trp495 would be explained by the requirement only for an aromatic residue in the interfacial region. In another membrane protein system, it has been inferred that there is a preference in the interfacial region on Trp relative to Phe [44]. This appears not to be the case for the colicin E1 channel protein.

Another case in the literature, where a critical defined single residue was photoinactivated, was His 245 in firefly luciferase 
[45]. However, it should be noted that the luciferase inactivation was sensitized by a specific photoinactivation reagent, namely, a firefly luciferin analogue, which binds directly to the luciferase active site. In contrast, the colicin photoinactivation studied here was mediated by reactive oxygen species, most likely singlet oxygen, generated upon excitation of a well-known non-specific photosensitizer, aluminum phthalocyanine. Therefore, this is the first case when distinct participation of a specific amino acid residue in the protein photoinactivation mediated by reactive oxygen species has been demonstrated using site-directed mutagenesis. The photodynamic inactivation of colicin channels is of particular interest due to recently revealed structural similarity of the colicin channel-forming domain to $\mathrm{Bcl}-\mathrm{x}_{\mathrm{L}}$, an inhibitor of apoptosis $[46,47]$. It may be suggested that the mechanism of colicin photoinactivation studied here is relevant to primary processes of photodynamic induction of apoptosis.

In conclusion, the results of this work have demonstrated for the first time that ionic channels formed by the toxin-like protein colicin E1 in lipid bilayers undergo light-induced inactivation in the presence of a photosensitizer which is mediated by reactive oxygen species. The data obtained here pointed to the direct damage of the channel-forming protein via modification of the specific tryptophan residue as a mechanism of sensitized photoinactivation of colicin E1.

Acknowledgements: The authors are thankful to A.A. Sobko for assistance in several experiments. This work was supported in part by Grants from the NIH: GM 18457 and Fogarty Award TW01235 (W.A.C.), and Grants from the RFBR: 00-04-48299 (Y.N.A.) and 01-04-06095 (T.I.R.)

\section{References}

[1] Dougherty, T.J. (1993) Photochem. Photobiol. 58, 895-900.

[2] Ochsner, M. (1997) J. Photochem. Photobiol. B Biol. 39, 118

[3] Valenzeno, D.P. (1987) Photochem. Photobiol. 46, 147-160.

[4] Girotti, A.W. (1990) Photochem. Photobiol. 51, 497-509.

[5] Pooler, J.P. and Valenzeno, D.P. (1979) Photochem. Photobiol. $30,581-584$

[6] Spires, S. and Begenisich, T. (1990) J. Gen. Physiol. 96, 757-775.

[7] Valenzeno, D.P. and Tarr, M. (1991) Membrane photomodification and its use to study reactive oxygen effects, in: Photochemistry and Photophysics (Rabek, J.F., Ed.), pp. 137-191, CRC Press, Boca Raton, FL.

[8] Duprat, F., Guillemare, E., Romey, G., Fink, M., Lesage, F., Lazdunski, M. and Honore, E. (1995) Proc. Natl. Acad. Sci. USA 92, 11796-11800.

[9] Kunz, L. and Stark, G. (1998) J. Membr. Biol. 166, 179-185.

[10] Salet, C., Moreno, G., Ricchelli, F. and Bernardi, P. (1997) J. Biol. Chem. 272, 21938-21943.

[11] Holmberg, S.R., Cumming, D.V., Kusama, Y., Hearse, D.J., Poole-Wilson, P.A., Shattock, M.J. and Williams, A.J. (1991) Cardioscience 2, 19-25.

[12] Xiong, H., Buck, E., Stuart, J., Pessah, I.N., Salama, G. and Abramson, J.J. (1992) Arch. Biochem. Biophys. 292, 522-528.

[13] Kunz, L. and Stark, G. (1997) Biochim. Biophys. Acta 1327, 1-4

[14] Kunz, L. and Stark, G. (1998) J. Membr. Biol. 166, 187-196.
[15] Strassle, M. and Stark, G. (1992) Photochem. Photobiol. 55, 461-463.

[16] Kunz, L., Zeidler, U., Haegele, K., Przybylski, M. and Stark, G. (1995) Biochemistry 34, 11895-11903.

[17] Rokitskaya, T.I., Antonenko, Y.N. and Kotova, E.A. (1993) FEBS Lett. 329, 332-335.

[18] Rokitskaya, T.I., Antonenko, Y.N. and Kotova, E.A. (1996) Biochim. Biophys. Acta 1275, 221-226.

[19] Rokitskaya, T.I., Antonenko, Y.N. and Kotova, E.A. (1997) Biophys. J. 73, 850-854

[20] Becker, M.D., Greathouse, D.V., Koeppe, R.E. and Andersen, O.S. (1991) Biochemistry 30, 8830-8839.

[21] Hu, W., Lee, K.C. and Cross, T.A. (1993) Biochemistry 32, 7035-7047.

[22] Wallace, B.A. (1996) Adv. Exp. Med. Biol. 398, 607-614

[23] Campos, A.M., Lissi, E.A., Vergara, C., Lanio, M.E., Alvarez, C., Pazos, I., Morera, V., Garcia, Y. and Martinez, D. (1999) J. Protein Chem. 18, 297-306.

[24] Lasalde, J.A., Tamamizu, S., Butler, D.H., Vibat, C.R., Hung, B. and McNamee, M.G. (1996) Biochemistry 35, 14139-14148.

[25] Schein, S.J., Kagan, B.L. and Finkelstein, A. (1978) Nature 276 $159-163$.

[26] Slatin, S.L. (1988) Int. J. Biochem. 20, 737-744.

[27] Cramer, W.A., Heymann, J.B., Schendel, S.L., Deriy, B.N., Cohen, F.S., Elkins, P.A. and Stauffacher, C.V. (1995) Annu. Rev. Biophys. Biomol. Struct. 24, 611-641.

[28] Elkins, P., Bunker, A., Cramer, W.A. and Stauffacher, C.V. (1997) Structure 5, 443-458.

[29] Straight, R.C. and Spikes J.D. (1985) Photosensitized oxidation of biomolecules, in: Singlet Oxygen (Frimer, A.A., Ed.), Vol. IV, Chapter 2, pp. 91-143, CRC Press, Boca Raton, FL.

[30] Michaeli, A. and Feitelson, J. (1994) Photochem. Photobiol. 59, 284-289.

[31] Krasnovsky Jr., A.A. (1998) Membr. Cell Biol. 12, 665-690.

[32] Biasutti, M.A., Soltermann, A.T. and Garcia, N.A. (2000) J. Peptide Res. 55, 41-50.

[33] Merrill, A.R. and Cramer, W.A. (1990) Biochemistry 29, 85298534.

[34] Steer, B.A. and Merrill, A.R. (1994) Biochemistry 33, 1108-1115.

[35] Lindeberg, M., Zakharov, S.D. and Cramer, W.A. (2000) J. Mol. Biol. 295, 679-692.

[36] Bishop, L.J., Bjes, E.S., Davidson, V.L. and Cramer, W.A. (1985) J. Bacteriol. 164, 237-244.

[37] Davidson, V.L., Brunden, K.R. and Cramer, W.A. (1985) Proc. Natl. Acad. Sci. USA 82, 1386-1390.

[38] Zakharov, S.D., Heymann, J.B., Zhang, Y.L. and Cramer, W.A. (1996) Biophys. J. 70, 2774-2783.

[39] Mueller, P., Rudin, D.O., Tien, H.T. and Wescott, W.C. (1963) J. Phys. Chem. 67, 534-535.

[40] Cleveland, M.V., Slatin, S., Finkelstein, A. and Levinthal, C. (1983) Proc. Natl. Acad. Sci. USA 80, 3706-3710.

[41] Spikes, J.D. (1986) Photochem. Photobiol. 43, 691-699.

[42] Yau, W.-M., Wimley, W.C., Gawrisch, K. and White, S.H. (1998) Biochemistry 37, 14713-14718.

[43] Ridder, A.N., Morein, S., Stam, J.G., Kuhn, A., de Kruijff, B. and Killian, J.A. (2000) Biochemistry 39, 6521-6528.

[44] Braun, P. and von Heijne, G. (1999) Biochemistry 38, 9778-9782.

[45] Branchini, B.R., Magyar, R.A., Martiashaw, M.H., Anderson, S.M. and Zimmer, M. (1998) Biochemistry 37, 15311-15319.

[46] Schendel, S.L., Xie, Z., Montal, M.O., Matsuyama, S., Montal, M. and Reed, J.C. (1997) Proc. Natl. Acad. Sci. USA 94, 51135118.

[47] Muchmore, S.W., Sattler, M., Liang, H., Meadows, R.P., Harlan, J.E., Yoon, H.S., Nettesheim, D., Chang, B.S., Thompson, C.B., Wong, S.L., Ng, S.L. and Fesik, S.W. (1996) Nature 381, $335-341$. 